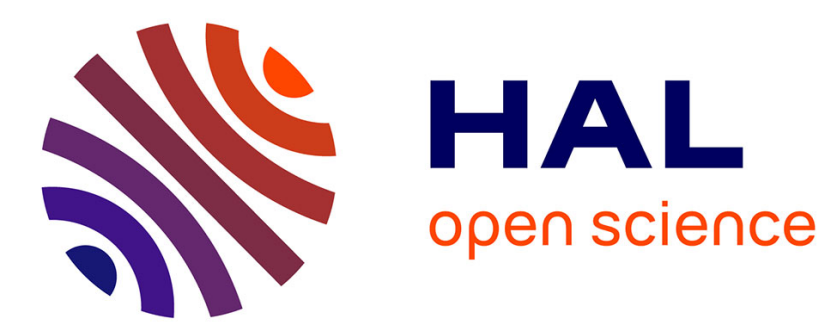

\title{
TOWARDS A SEMANTICS FOR THE ARTIFACTUAL THEORY OF FICTION AND BEYOND
}

M Fontaine, Shahid Rahman

\section{- To cite this version:}

M Fontaine, Shahid Rahman. TOWARDS A SEMANTICS FOR THE ARTIFACTUAL THEORY OF FICTION AND BEYOND. Synthese, 2014, 16 (1), 10.1007/s11229-013-0287-z • halshs-01216164

\section{HAL Id: halshs-01216164 \\ https://shs.hal.science/halshs-01216164}

Submitted on 19 Oct 2015

HAL is a multi-disciplinary open access archive for the deposit and dissemination of scientific research documents, whether they are published or not. The documents may come from teaching and research institutions in France or abroad, or from public or private research centers.
L'archive ouverte pluridisciplinaire HAL, est destinée au dépôt et à la diffusion de documents scientifiques de niveau recherche, publiés ou non, émanant des établissements d'enseignement et de recherche français ou étrangers, des laboratoires publics ou privés. 


\title{
TOWARDS A SEMANTICS FOR THE ARTIFACTUAL THEORY OF FICTION AND
}

\author{
BEYOND. By M. FONTAINE AND SHAHID RAHMAN (PREPRINT)
}

\begin{abstract}
In her book Fiction and Metaphysics [1999] Amie Thomasson, influenced by the work of Roman Ingarden, develops a phenomenological approach to fictional entities in order to explain how non-fictional entities can be referred to intrafictionally and transfictionally, for example in the context of literary interpretation. As our starting point we take Thomasson's realist theory of literary fictional objects, according to which such objects actually exist, albeit as abstract and artifactual entities. Thomasson's approach relies heavily on the notion of ontological dependence, but its precise semantics has not yet been developed. Moreover, the modal approach to the notion of ontological dependence underlying the Artifactual Theory has recently been contested by several scholars. The main aims of this paper are (i) to develop a semantic approach to the notion of ontological dependence in the context of the Artifactual Theory of fiction, and in so doing bridge a number of philosophical and logical gaps; (ii) to generalize Thomasson's categorial theory of ontological dependence by reconstructing ontological categories of entities purely in terms of different structures of ontological dependence, rather than in terms of the basic kinds of entities the categorical entities depend on.
\end{abstract}

Keywords: artifactual theory, ontological dependence, fiction, non-existence.

\section{Introduction}

In her book Fiction and Metaphysics [1999] Amie Thomasson, influenced by the work of Roman Ingarden, develops a phenomenological approach to fictional entities in order to explain how non-fictional entities can be referred to intrafictionally and transfictionally, for example in the context of literary interpretation. The main aims of this paper are (i) to develop a modal-semantic approach to the notion of ontological dependence in the context of the Artifactual Theory of fiction, and in so doing bridge a number of philosophical and logical gaps; (ii) to generalize Thomasson’s categorial theory of ontological dependence by reconstructing ontological categories of entities purely in terms of different structures of ontological dependence, rather than in terms of the basic kinds of entities the categorical entities depend on. 


\section{Fictional Entities as a Result of Creation}

The key to Thomasson's realist approach to literary fictional entities lies in her acknowledging their full ontological status, i.e., considering them as denizens of our world, like armchairs, elephants or galaxies. According to Thomasson, fictional entities are inhabitants of the actual world just as non-fictional ones are. On the one hand, they are creations, or more precisely, artifacts, and as such, existent objects, like tables or buildings. ${ }^{1}$ On the other hand, they are abstract creations, like marriages, universities and theoretical entities postulated by physical theories, and are tied to the everyday world by their dependence on readers, authors and copies of texts.

In her book Fiction and Metaphysics, Thomasson identifies several types of ontological dependence. We will confine our discussion to only two of these, namely historical and constant dependence. These have their roots in Ingarden [1931, 1968], who made a distinction between derivation, i.e., the dependence of an entity on another in order to come into existence, and contingency, or the dependence of an entity on another in order to remain in existence. We will classify these as types of ontological dependence. ${ }^{2}$ According to Ingarden, a fictional character is created by an author who constructs sentences about it. Fictional entities thus have a derivative dependence on their creators. Yet they are considered to be kept in existence thereafter not by the imagination of any individual, but by words and sentences:

We can begin by distinguishing between constant dependence, a relation such that one entity requires that the other entity exist at every time at which it exists, from historical dependence, or dependence for coming into existence, a relation such that

\footnotetext{
${ }^{1}$ As we will discuss further on in the paper, instead of creation we speak of codification.

2 In fact, Thomasson speaks of existential dependence. Saying that $\mathrm{Y}$ existentially depends on $\mathrm{X}$ could suggest that the existence of $\mathrm{Y}$ entails the simultaneous existence of $\mathrm{X}$; this precisely need not be the case in connection with historical dependence. The idea that $\mathrm{Y}$ depends for its existence on $\mathrm{X}$ is, we think, somewhat more conveniently expressed when speaking of ontological dependence.
} 
one entity requires that the entity exist at some time prior to or coincident with every time at which it exists.

[Thomasson 1999: 29]

Thomasson combines the notions of historical and constant dependence with the idea of rigid and generic dependence. The fictional character Holmes is historically dependent on Conan Doyle. Moreover, the ontological dependence is, in this example, of a rigid kind: Holmes depends historically on one fixed individual, namely Conan Doyle. After Conan Doyle’s death Holmes survives as an abstract artifact because Holmes is ontologically sustained by copies of Conan Doyle's texts, as we will discuss below - the dependence on copies is of a generic kind since there is no fixed copy on which Holmes depends.

\section{Ontological Requirement in a Modal-Temporal Framework}

Thomasson's use of the notion of ontological dependence strongly suggests that if we set this notion in a formal semantic framework it should be thought of in modal terms. Moreover, the corresponding semantic framework can be developed within a structure (i.e., the Cartesian product) of possible worlds and moments of time. Thomasson writes:

Assuming that an author's creative acts and literary works about the character are also jointly sufficient for the fictional character, the character is present in all and only those worlds containing all of its requisite supporting entities. If any of these conditions is lacking, then the world does not contain the character. If Doyle ${ }^{3}$ does not exist in some world, then Holmes is similarly absent. If there is a world in which Doyle's work were never translated at all and all of the speakers of English were killed off, . . . then Sherlock Holmes also ceases to exist in that world . . .

\footnotetext{
${ }^{3}$ Actually, the relevant author's surname is 'Conan Doyle'.
} 
Indeed, it is a semantic consequence of Thomasson's approach that the artifactual feature of fictional entities becomes clear only in connection with the assumption of a multitude of worlds. This is because they are ontologically dependent entities. Any such entity requires, for its existence, another entity - its maker - whereas the converse requirement does not prevail. Again, the notion of requirement only receives its sense in relation to a number of possible worlds. That $\mathrm{X}$ requires $\mathrm{Y}$ means that in each of those several worlds, $\mathrm{X}$ exists only if Y does. For instance, Sherlock Holmes exists only in those worlds in which Conan Doyle exists or has existed, even if there are possible worlds and times in and at which Conan Doyle exists but Sherlock Holmes does not.

Thomasson's definition of ontological dependence is based on what we might call a modal requirement relation. ${ }^{4}$ We begin by distinguishing different sorts of rigid modal requirements, and then, in the following sections, we introduce the corresponding definitions of ontological dependence based on the modal requirement relations. To avoid misunderstandings, Thomasson neither developed a formal semantics nor deployed the distinctions we introduce below.

When describing the notion of dependence, we take the relevant structure of worlds and times to be a framework $(\mathrm{W}, \mathrm{R}, \mathrm{T},<)$ consisting of a set of worlds, $\mathrm{W}$, ordered by an 'accessibility relation', $\mathrm{R}$, and a set of times, $\mathrm{T}$, ordered by an earlier than relation, $<.{ }^{5}$ The relation $\mathrm{R}$ can be interpreted in different ways depending on how we wish to delimit our notion of dependence. In particular, the more accessible the worlds, the stronger the notion of dependence. To mention a couple of examples, $\mathrm{R}$ might be determined via epistemic considerations, or it could encode what is compatible with a physical theory, or what is

\footnotetext{
${ }^{4}$ What we refer here to as modal requirement is actually the same as Simons's weak foundation [1987: 295]. For the sake of generality, we have opted for a more neutral terminology.

${ }^{5}$ For the sake of simplicity, we assume that the relation $\mathrm{R}$ is invariant with respect to times, and that the relation $<$ is invariant with respect to worlds. Conceptually there would be no difficulty in allowing the time structure to vary with the world being considered, and allowing the set of worlds accessible from a given world to be contingent on the time being considered.
} 
'historically possible'. The only restriction on $\mathrm{R}$ is that it must have a suitable relationship with the ontological category of fictional entities and other artifacts. If an artifact is created in $w$, and $v$ is R-accessible from $w$, then the artifact must be related in a certain way to its creator in $v$ as well. Further details on this point will be provided when we discuss the notion of uniform historical requirement below.

We assume that each world-time pair $(w, t)$ is associated with a set of individuals, denoted $\mathrm{D}_{w, t}$, and termed the domain of the world $w$ at the time $t$. Intuitively, then, the domain consists of those individuals that exist in world $w$ at time $t$. The domains of distinct worldtime pairs may but need not overlap. ${ }^{6}$ Given a framework (W,R,T,<), when we speak of individuals without specifying a world and a time, we mean any inhabitant of some of the relevant domains, i.e., an element of the set $\cup_{(w, t) \in W \times T} D_{w, t}$.

We wish to use our modal-temporal framework to capture what Thomasson calls 'historical rigid dependence'. Let us begin with the following, more general notions.

[D1] [Local Modal REQUiREMENT] We say that X locally requires $Y$ in world $w_{0}$ at time $t_{0}$ iff the following condition holds: if X exists in $w_{0}$ at $t_{0}$, then Y exists in $w_{0}$ at $t_{0}{ }^{7}$

Of course, this condition holds vacuously if $\mathrm{X}$ does not exist in $w_{0}$ at $t_{0}$, but otherwise it imposes the condition that $\mathrm{Y}$ exist in $w_{0}$ at $t_{0}$ as well. We may now formulate the notions of rigid and constant generic requirement.

[D2] [Historical Rigid Modal ReQuirement] X historically RigidLy MODALly REQUIRES $\mathrm{Y}$ in world $w_{0}$, iff for every world $w$ that is R-accessible from $w_{0}$ there is a time $t^{*}$ such that for all times $t$, the following condition holds: if $\mathrm{X} \in \mathrm{D}_{w, t}$, then:

- $t^{*} \leq t$ and

- $\mathrm{Y} \in D_{w, t^{*}}$

\footnotetext{
${ }^{6}$ This is the way the domains of worlds are usually looked upon when, in the semantics of first-order modal logic, so-called varying domain models are used.

7 The notion of local requirement seems to cover some of the reflexive cases of metaphysical dependence discussed by Jenkins [2011].
} 
- $\mathrm{X} \in D_{w, s}$ for every time s with $t^{*} \leq s \leq t$.

The fact that $\mathrm{X}$ historically requires $\mathrm{Y}$ in $w_{0}$ means, then, that in all the accessible worlds, $\mathrm{X}$ exists uninterruptedly from some time $t^{*}$ onwards, with Y existing at $t^{*}$. The time $t^{*}$ may vary with the world $w$ being considered. This still leaves open the possibility that Conan Doyle's time of birth varies with the possible world he inhabits. It is worth noting that the relation defined by [D2] is not yet a relation of ontological dependence that could be deployed in the context of fictions. However, [D2] will be used further on to render an adequate notion of ontological dependence.

In the context of the Artifactual Theory, the existence of literary fictional entities is assured by the constant generic dependence on copies. In order to define this kind of dependence we will start by focusing on the notion of constant generic requirement. Unlike the term historical rigid modal requirement, the term constant generic modal requirement is to be understood as a relation to a specific set of objects, called genus:

[D3] [Constant Generic Modal Requirement] Let $\Gamma \cup\{\mathrm{X}\}$ be a set of individuals of size greater than one, where each individual exists in at least one world which is R-accessible from $w_{0}$. . We can then say that X CONSTANTLY AND GENERICALLY MODALLY REQUIRES SOME ELEMENT OF $\Gamma$ at $w_{0}$ iff the following condition holds for all worlds $w$ R-accessible from $w_{0}$ and all times $t$ :

If $\mathrm{X} \in \mathrm{D}_{w, t,}$, then there is a $\mathrm{Y} \in \Gamma$ such that $\mathrm{Y} \in \mathrm{D}_{w, t}$.

The main underlying idea is that if a fictional character exists at a given time $t$, then at least one other object (say, copies of the book) of a given set must exist at that same time $t$. However, in order to capture the idea of constant dependence in its full generality further distinctions are required (see section 6). 
If $\Gamma$ is a singleton we speak of constant rigid requirement, while if it is of any greater size we speak of a constant generic requirement. Moreover, Thomasson [1999: 25-26] admits reflexive cases of constant rigid requirement in principle and points out that the notion of ontological dependence should be isolated from the whole-part relation. ${ }^{8}$ The idea is that the study of the mereological relation should not be intermixed with ontological issues such as whether a part could or could not exist without the (corresponding) whole. We will follow Thomasson's strategy on this point and will only study cases of dependence that are ontological and not mereological in nature. This does not mean that one could not study the interplay between both at some later stage - but we will not undertake such a study in the present paper.

The elements of the formal semantics referred to above will not suffice if our aim is to characterize fictional entities as artifacts in a modal framework. Indeed, the definitions [D1], [D2], [D3] inherent in the notion of modal requirement do not preclude cases of reflexivity or symmetric ontological requirement relations. Moreover, the formulation of generic dependence in [D3] does not capture the idea that each copy, on its own, suffices for the existence of the corresponding fictional entity. Thomasson acknowledges these facts and, as we discuss below, proposes linking the notion of modal requirement with an underlying ontology. Thus, one way of viewing Thomasson's approach to fictional literary entities is to say that ontological dependence results from the assumption of some primitive ontological distinctions that restrict the notion of modal requirement. We will not follow Thomasson's strategy, but rather develop a more general alternative. Nonetheless, let us first examine the problematic cases recorded in the literature, and the responses that Thomasson's own approach provides.

\footnotetext{
${ }^{8}$ In her informal discussion on the notion of constant dependence, Thomasson points out some cases of constant rigid requirement: 'Not only may the objects be identical (everything is constantly dependent on itself . . . an object may also be rigidly constantly dependent on one of its own parts or moments: for example ... on my brain.' [Thomasson 1999: 30]
} 


\section{Challenges to Modal Approaches}

Beyond trivialization by reflexivity there are other problems posed by Thomasson's approach that jeopardize the relevance of the notion of ontological dependence as defined in modal terms and which have been identified by Simons [1987] and Fine [1995], among others, and further investigated by Correia [2005]. These include:

a) Reflexivity: every object always requires itself for its existence (in our framework this is possible in the case of local requirement).

b) Compresence: even though two objects exist together concurrently in exactly the same worlds, this does not mean that one of them is ontologically dependent on the other (by the mere fact of being compresent) - it is not the case, for example, that Holmes and Watson are mutually and ontologically dependent, even though they always occur together. Fine [1995: 271, 275] illustrates the point by means of the necessary compresence of the individual, Socrates, and the singleton \{Socrates\}. Necessarily, if one exists, the other does. However, despite the compresence, it seems reasonable to claim that \{Socrates\} depends on Socrates while the converse is not true. Indeed, while the existence of Socrates is helpful to explain the existence of $\{$ Socrates\}, i.e., the set that has Socrates as its element, we would not attempt to explain the existence of Socrates by means of the existence of the singleton, \{Socrates\}. Additionally, the notion of compresence is ambiguous: depending on the story, it can mean that $\mathrm{X}$ and $\mathrm{Y}$ are compresent (in the story, $\mathrm{X}$ never occurs without $\mathrm{Y}$ and vice versa); but it can also mean that they are compresent from a perspective outside the fictional work. If Sherlock Holmes is present in the actual world qua a fictional entity, then so is Moriarty, although in the story Moriarty is not always present when Holmes is. It is the latter, external, sense of compresence that is relevant for the notion of ontological dependence. 
c) Right-Irrelevance: Let us assume that there is a necessarily existent entity. Given that if $X$ exists, then $Y$ exists is trivially true if $\mathrm{Y}$ is a necessary entity, does everything depend on this entity? ${ }^{9}$ If this is so, and if we admit that numbers are necessary entities, then we must admit - as Pythagoreans once did - that everything is dependent on numbers. However, if we take the notion of creative act seriously, it is unlikely that we would be willing to accept that Holmes depends on the number $2 .^{10}$

d) No fixed point for the historical dependence: Mythological characters, such as Zeus, or even some fairy-tale characters, such as Snow White, do not appear to have been created by any specific person at any specific time. Rather, they are supported by a more or less clearly delineated process of creation. Thomasson acknowledges this difficulty herself and says that sometimes the creation process is diffuse (1999:7, 140, footnote 3). According to Voltolini [2006: 49-64] the possible lack of a fixed point is a sign of a deeper problem that seems to undermine the usefulness of Thomasson's notion of creation for matters of reference and identity (we discuss this issue in 5.1 below).

The following two objections are connected with the whole-part relation which, as mentioned above, will not be addressed in this paper. However, these objections help us to understand the nature of constant generic ontological dependence, as we will discuss further on.

e) Mereological whole-part relations: Readers will recall the well-known identity paradox known as the Ship of Theseus, described by Plutarch. The Ship of Theseus had been kept in Athens harbour for a very long time as a vestige of the battle against the Minotaur. Athenians preserved the ship by replacing all of its wooden parts until it was practically impossible to distinguish between the original parts and the new parts. Plutarch asks

\footnotetext{
${ }^{9}$ This has been pointed out by Fine [1995: 271] and discussed by Correia [2005: 45 ff.]

10 Correia adds a further problem (that stems from Fine [1995: 271] called left-irrelevance based on the trivial truth of conditionals involving objects that are necessarily inexistent (Correia [2005: $42 \mathrm{ff}$.$] ).$
} 
whether it is still the same ship or not. In our case, the point is that if we do not exclude the mereological relation in definition [D3], we might be forced to accept that a ship constantly and generically requires its parts, even if all of its parts are progressively replaced. A modern version of the paradox uses our body as an example: our body is constantly dependent on our cells even though the initial cells might have changed completely in the course of our lifetime.

f) Proper part. Let us assume that one entity, say an armchair, is a proper part of one element, say a building, of the set genus $\Gamma$ ([D3]) and that all the other elements of $\Gamma$, say, a city and country, contain the building. In this case, the armchair is constantly dependent on $\Gamma^{11}$

All of these counterexamples are symptomatic of the lack of a notion of ontological priority in the notion of ontological dependence formulated so far. For example, if we admit that \{Socrates\} depends on Socrates and not the inverse, it is because we somehow take it that Socrates has a kind of ontological priority over the singleton $\{$ Socrates\}.

Ontological priority has led some authors - notably Fine [1995 $]^{12}$ and Lowe [1994, $1998]^{13}$ - to combine essentialism and ontological dependence. Lowe defines the ontological dependence of $\mathrm{X}$ upon $\mathrm{Y}$ as $\mathrm{X}$ is essentially related to $\mathrm{Y}$ : it is part of the essence of $\mathrm{X}$ that if it exists, (it is because) Y exists. Correia [2005: 57] further develops the idea of ontological priority, taking as primitive the notion of metaphysical grounding. ${ }^{14}$ As mentioned above, Thomasson [1999: 26] proposes linking the notion of ontological dependence to a specific ontology:

\footnotetext{
11 Tero Tulenheimo formulated this objection in a talk at the workshop Modalities: Semantics and Epistemology. MESHS-Lorraine, 3-12-2010, Nancy.

12 'Then the present proposal is that the dependence of $x$ upon $y$ should be defined by $\square x(E x \rightarrow E y)$ ' [Fine 1995: 273]; this reads: it is true in virtue of the essence of $X$ that if $X$ exists $Y$ exists.

${ }^{13}$ See also Cameron [2008], Rosen [2010] and Schaffer [2009].

14 'When we say that $X$ depends on $Y$, we mean not only that $X$ requires $Y$, but also that $X$ exists in virtue of $Y$, i.e. $Y$ grounds to the existence of $X$.' [Correia 2005: 57] We will make use of an alternative definition of grounding.
} 
Entities can be more clearly and appropriately classified in terms of what they depend on rather than in terms of whether or not they are dependent.

In fact, her approach is based on the ontological characterization of the second term of the relation $X$ depends on $Y$. More precisely, Thomasson defines a double system of ontological categories ${ }^{15}$ based on dependence on concrete entities on the one hand and dependence on mental states on the other.

According to Thomasson, what is required by a fictional entity is not only an author as a concrete entity, but also a mental state by which it comes into existence. In such an ontology the fictional character Holmes does not depend on itself since it is not a concrete entity. For the same reason Socrates (the individual) does not depend on the singleton \{Socrates\} - i.e., it does not depend on the set but does depend on its only element - and neither does Holmes depend on Watson, even if they are compresent. ${ }^{16}$ This approach does not solve the right-relevance problem if we are willing to accept in our models entities that are both necessary and spatiotemporal, ${ }^{17}$ nor is it clear how the case of a literary character resulting from a previously existing tradition should be dealt with (see objection $d$ above). The latter objection might challenge the very idea of creation underlying the Artifactual Theory, since Thomasson would claim that different, say, Snow Whites of different authors are different fictional entities. Moreover, the theory might perhaps leave room for the creation of a character by a cultural community during some fixed intervals of time. Authors might refer to those characters (produced by some cultural community) through some adapted form of Kripke’s initial baptism act. ${ }^{18}$. To us it seems natural - at least in the context of literary fictions - to make use of the more neutral notion of codification that is also

\footnotetext{
${ }^{15}$ Thomasson [1999: 25-26] calls it a 'bi-dimensional' system of ontological categories.

${ }^{16}$ For further details on Thomasson’s ontology, see [Thomasson 1999: Part Two - Ontological Decisions].

${ }^{17}$ However, Thomasson's ontology precludes the idea that objects could be ontologically dependent on numbers.

${ }^{18}$ For objections to the identification and reference criteria provided by Thomasson's approach, see Kroon/Voltolini [2011: paragraph 1.3] and Voltolini [2006].
} 
compatible with a non-Kripkean approach to the reference of singular terms, as we will discuss further on.

Our proposal, as developed below, not only provides a formal semantics for Thomasson's Artifactual Theory, but also introduces a more general notion of ontological dependence compatible with a position which on the one hand accepts that literary fictional entities are artifacts but on the other might reject Thomasson's view that they are existent entities.

\section{From Historical Requirement to Historical Dependence}

\subsection{Historical Requirement and Codification}

As already mentioned, Thomasson links the notions of ontological dependence to a specific ontological classification. Indeed, she claims that Holmes is historically rigidly dependent not only on Conan Doyle, but also on the mental state of Conan Doyle at the time of creation. Thus, in Thomasson's approach, historical modal requirement (see [D2] above) becomes historically rigid dependence by the specification of both the author and his or her appropriate mental state during the time of creation. The idea is that not only are fictional characters abstract artifacts, created at a fixed point in time, but that part of their identity is also given by its link to the creator (this differentiates fictional characters from other abstract entities such as certain scientific concepts).

Now, according to the Artifactual Theory, this fixed point in time is the time of the creation of a fictional entity, but this might give rise to the objection d mentioned in section 4 that some fairy-tale characters, such as Snow White, do not appear to have been created by any specific person at any specific time. Rather, they are supported by a more or less clearly delineated process of creation and in this case the assumption of a Kripkean-baptism act does not seem to be very helpful. More generally, as thoroughly discussed by Voltolini [2006: 49- 
64], the possibility of a pre-existent intentional object before a fictional character is created by an author seems to undermine Thomasson's notion of creation. ${ }^{19}$ Indeed, it is not only the case that Snow White pre-existed before Grimm's tale, but also that Holmes must have been existent as an intentional object, as an object of thought, before Conan Doyle finished his (first) work. Thus, instead of an act, it looks as if Thomasson requires that it be accepted that this act is rather a make-believe process specific to each fictional character. Unfortunately the worries do not end there, since if it is a process, the reference can not achieved by a fixed set of properties described by the correspondent make-believe: the set of properties might evolve. $^{20}$

As mentioned above, we do not share Thomasson’s [1999] (Kripkean) approach to identity. We cannot develop our own conception of identity here, since the main aims of the present paper relate to the task of providing a modal semantics for the notion of ontological dependence in the framework of the Artifactual Theory. The notions of individual and transworld identity in the context of the Artifactual Theory are the subject of another publication by the authors of the present article (Fontaine and Rahman [2012]). Nevertheless, in order to address the criticism of the type raised by Voltolini we will undertake the following move:

- We will not (necessarily) fix the point at which the historical dependence is defined as the time of the mental (creation) act (of the correspondent author), but rather as the point (or interval) when the first literary work by a given author was finished and made public. For reasons given below, we will call this time-point (or

\footnotetext{
${ }^{19}$ See Kroon and Voltolini [2011: paragraph 1.3].

${ }^{20}$ Voltolini's [2006: 65-1000] own syncretistic theory combines the theory of the Neo-Meinongians with the Artifactual Theory.
} 
time-interval) the time-point of the codification act. ${ }^{21}$ This renders sufficient and necessary conditions for the required notions of ontological dependence.

Certainly this move does not solve the problem of reference and identity. In principle, though, the definitions of ontological dependence given below seem to be compatible with both a rigid-designation approach and one that completely rejects the Kripkean framework, such as Hintikka's world-lines. For the general approach of the artifactual theory, however, the notion of rigid-designation is problematic, particularly in the case of negative existentials and of literary characters linked with real individuals (as in the case of Tolstoy's Napoleon $)^{22}$.

According to our view, what the brothers Grimm did was to write, finish and make public a story describing the fictional character and by this very act - or even process - a canonical fictional entity called Snow White - publicly known as Grimm's Snow White came to be part of the world's literature. The point is that it might well be the case that before the story was written, an intentional object pre-existed as part of a pre-existing story-telling process either of another author or the same author. However, for the conception of the fictional character as a public cultural ontologically dependent object, the process that culminates in the production of the story is sufficient. The different ways in which reference is established (either by Kripkean chains or by other devices) will link Grimm’s Snow White with the first relevant story of those authors. The author might explicitly identify the earlier character on which his (her) codification act was based, or this reference might be inferred by the reader or an expert in literature from background knowledge (see conclusion). The term

\footnotetext{
${ }^{21}$ The term 'codification' was suggested to us by Prof. Göran Sundholm in a personal communication during his visiting professorship at the University of Lille 3-Charles-de-Gaulle from February to April 2012. In fact, Thomasson [1999: 12-13] comes very close to this notion when she speaks of creations as linguistic acts.

${ }^{22}$ In her more recent work Thomasson [2003] tackles such issues with help of the distinction between de re and de dicto pretense. In our view Hintikka's world-lines provide a more general solution.
} 
codification should signalize that the conception of fictional characters as ontologically dependent objects (artifacts) does not necessarily require the precise identification of a fixed mental act of creation, but only the identification of a completed linguistic act (or process) that has been made public. What the author does when he writes the story is to fix a codex, or set a canon, ${ }^{23}$ by means of which, once the story has been written, an institutionalized ${ }^{24}$ process of make-believe ${ }^{25}$ is triggered that is specific to each fictional character and to the author's way of structuring that process. ${ }^{26}$

The point of identifying the codification act is that it provides the relevant makebelieve process with a fixed reference point (or fixed reference interval), namely the moment (interval) when the act of writing down the story was completed. The make-believe process can certainly continue afterwards, but the reference point is still the first codification act. When completed, each codification act by any given author yields specific fictional entities. 27 Accordingly, the codification act allows us to speak of Sophocles' Electra and of Aeschylus' Electra and provides the basis on which similarities and differences can be established. $^{28}$

\footnotetext{
${ }^{23}$ Another way to see this is that the codification act provides a canonical element of a given type (as in constructive type theory) and that the definition of that canonical element associates the author with a fixed time-point.

${ }^{24}$ By institutionalized make-believe process we mean that the codification act establishes within a cultural community a set of norms involving a specific process of make-believe.

${ }^{25}$ For the notion of make-believe see Walton [1990].

${ }^{26}$ This feature of the act of codification has the consequence that the artifactual conception of a fictional character requires some form of characterizing properties. See definition 10.

27 This assumes an appropriate theory of identity

${ }^{28}$ It might be objected that if institutionalization is what makes a fictional character come into reality, and institutionalization is something that happens in degrees, then also the coming into reality of fictional characters happens in degrees. Was Holmes not completely real when ten people had read the story, but completely real when ten thousand people had? This objection was raised by an anonymous reviewer.

According to our viewpoint, the case is similar to the case of vague predicates such as being bald: despite the fact that there are border cases there is a frontier beyond which a person is definitely bald. In the case of fictional characters, there is a moment, or at least this is our assumption, beyond which the fictional character comes into reality as an ontologically dependent object. For fictional characters of literature we might, for example, say that it is the date of the first publication of the work. The point is that we assume that there is such a moment - it is even possible to speak of a closed interval instead and reformulate our definitions accordingly the precise description of which depends on the fictional character under consideration. Furthermore, we do not think that we need to accept that there are degrees of coming into reality of the fictional character - and in our framework there are no degrees of ontological dependence.
} 
[D4] [UNIFORM HistoricAl Rigid REQUiREMENT] In the special case where there is a fixed time $t^{*}$ such that for all worlds $w$, R-accessible from world $w_{0}$, and for all times $t$, the three conditions of historical rigid modal requirement [D2] hold, we say that X uniformly historically rigidly requires $\mathrm{Y}$ in $w_{0}$.

Uniform historical rigid requirement, then, is otherwise the same as historical rigid modal requirement, except that the time $t^{*}$ is the same for all worlds considered. In our analysis it is the uniform historical requirement that is relevant in connection with artifacts understood as ontologically dependent entities. Note that in cases of uniform historical rigid requirement as defined above, the time $t^{*}$ is uniquely determined: if $\mathrm{X}$ uniformly historically rigidly requires $\mathrm{Y}$ in $w_{0}$, there is exactly one time $t^{*}$ satisfying the three conditions. We take literary artifacts to be in a relation of uniform historical rigid requirement par excellence: we consider their relation to their author to be so strong that in every accessible world their identity is, as it were, conditioned by a fixed time $t$. This is a known position in the field of the theory of literature, and one of the main tenets of Thomasson's approach [1999: 56], according to which the fictional character Quijote of Cervantes and the fictional character Quijote of Menard are two different fictional entities.

Accordingly, since Sherlock Holmes uniformly historically rigidly requires Conan Doyle, we take it to be a part of Holmes's being an artifact that his time of codification remains the same in all accessible worlds in which Holmes exists. Note that we are not saying that Holmes could not have been codified (by Conan Doyle) at a different time. We are only saying that once Holmes was codified, this time serves as a fixed point of reference. Had Holmes been codified by Conan Doyle in another world, the time associated with his uniform historical rigid requirement relative to that world might very well be different. The relation of 
uniform historical dependence is neither transitive nor reflexive. However, if $\mathrm{X}$ uniformly historically rigidly requires some $\mathrm{Y}$, then $\mathrm{X}$ also uniformly historically rigidly requires itself.

\section{2 Historical Dependence}

Sherlock Holmes and Dr. Watson are both fictional entities that uniformly historically require Sir Arthur Conan Doyle in the actual world. Suppose, for the sake of illustration, that Holmes and Watson exist without exception in the same possible worlds at the same times, i.e., that they are 'compresent'. This implies - together with the information that both were created (codified) - that according to Definition [D4], Holmes uniformly historically requires Watson, and Watson uniformly historically requires Holmes. So [D4] allows symmetric cases and we are confronted with objection b of the preceding section. We suggest that the notion of the dependence of a fictional entity on its creator (codifier) is captured by the notion of uniform historical rigid dependence. ${ }^{29}$

\section{[D5] [Uniform Historical Rigid Dependence] We say that $\mathrm{X}$ UNIFORMLY} HISTORICALLY RIGIDLY DEPENDS ON $\mathrm{Y}$ at $w_{0}$ iff $\mathrm{Y}$ is a non-necessary individual such that $\mathrm{X}$ UNIFORMLY HISTORICALLY RIGIDLY REQUIRES $\mathrm{Y}$ at $w_{0}$ and there is no individual $\mathrm{Z}$ such that both X and Y UNIFORMLY HISTORICALLY RIGIDLY REQUIRE Z at $w_{0 .}{ }^{30}$

The relation of uniform historical rigid dependence is irreflexive and asymmetric, but it is not transitive. This definition introduces a notion of ontological priority. For example, Holmes and Watson are uniformly historically dependent on Conan Doyle, but they are not

\footnotetext{
${ }^{29}$ Correia [2005] stresses the fact that the notion of existential or ontological dependence is not symmetric and therefore cannot be defined as the relation ' $\mathrm{X}$ requires $\mathrm{Y}$ ' (in the sense specified at the beginning of the present section). He defines an asymmetric relation of simple dependence making use of the primitive notion of grounding. The asymmetric notion with which we operate, that of uniform historical rigid dependence, is again defined using exclusively the notion of uniform historical requirement, itself admitting of symmetric cases. Our notions are intrinsically modal (in that they receive their sense in the context of a plurality of worlds), while Correia's notion of grounding is not. Simons [1987: 295] adds explicit restrictions to the notion of dependence, such as reflexivity and necessary entities, but his definition does not preclude dependence between compresent entities.

${ }^{30}$ For the sake of simplicity we have restricted the definition to one entity $\mathrm{X}$, but in fact we could generalize to some series of entities $\mathrm{X}_{1} \ldots \mathrm{X}_{\mathrm{n}}$ - consider the case of joint authors.
} 
uniformly historically dependent on each other, even if compresent. Indeed, Watson cannot be D5-dependent upon Holmes since there is a Z, namely Conan Doyle, required by both in the sense of [D4]. Moreover, Conan Doyle is dependent upon his mother in the sense of [D2], but should Conan Doyle have a twin brother, Conan Doyle would not historically and rigidly depend on him (even if we assumed that such a twin brother were compresent with Conan Doyle). Similar remarks apply to Fine's counterexample of the compresence of Holmes and the singleton $\{$ Holmes (see objection b in section 4). Necessary entities are explicitly ruled out, ${ }^{31}$ so that right-irrelevance (see objection c in section 4) cannot take place. To obtain cases of uniform historical rigid dependence in the sense of definition [D5] when looking for entities satisfying the right part of the dependence relation, we must restrict our attention to individuals that are not necessary. If there are cases where we would like to consider a necessary being upon which an individual is dependent in the sense of [D5], the sense of 'dependence' would in any event, arguably, be different from that considered here. The main metaphysical assumption here is that we take it that fictional characters are the result of the codification act of contingent beings.

\section{Generic Constant Dependence}

The relation of constant dependence is crucial for the continued existence and death of fictional characters. In this sense a fictional character depends on copies of the works of the author who created it in the first place. In this respect, constant dependence is typically generic: no single copy of a literary work alone supports the continued existence of a fictional character such that the destruction of that copy would automatically imply the annihilation of the character. Instead, constant dependence pertains to the totality of all copies of a text introducing the character. Those copies are jointly responsible for its continued existence and

\footnotetext{
${ }^{31}$ A similar restriction has been deployed by Simons [1987: 295].
} 
the character survives the destruction of any number of copies as long as at least one remains. ${ }^{32}$ The generic nature of constant dependence serves to clarify the abstract character of literary works. Let us again quote Thomasson:

A literary work is only generically dependent on some copy (or memory) of it. So although it may appear in various token copies, it cannot be identified with any of them because it may survive the destruction of any copy, provided there are more. Nor can it be classified as a scattered object where all of its copies are, because the work itself does not undergo any change in size, weight, or location if some of its copies are destroyed or moved ...

But copies of the text are the closest concrete entities on which fictional characters constantly depend . . . Because they are not constantly dependent on any particular spatiotemporal entity, there is no reason to associate them with the spatiotemporal location of any of their supporting entities.

According to our understanding of the Artifactual approach, the abstract feature of fictional entities is linked to their generic dependence on concrete entities and to the fact that - in contrast with concrete entities - they are not constantly rigidly dependent on themselves. ${ }^{33}$ Those individuals belonging to the set $\Gamma$ (the genus) that co-exist with $\mathrm{X}$ in a given world $w$ at a given time $t$ are said to ontologically support $\mathrm{X}$ in that world at that time. However the

\footnotetext{
${ }^{32}$ This condition should be expressed perhaps in epistemic terms. Once brought into existence, a fictional character exists as long as at least one copy of the relevant text is known to exist by the relevant cultural community. It is, then, one of the characteristics of a fictional object that its existence is partly conditioned by our knowledge of it. This would involve a considerably more complex framework than the one developed in the present paper.

33 Thomasson (1999: 26) herself is less sharply cut on the issue. On the one hand, she concedes that it is trivial that everything depends on itself for its own existence, but on the other hand she writes that this is not at all useful:
}

Apart from its triviality, one motivation for excluding cases of self-dependence seems to be in the interest of distinguishing the so-called dependent from independent entities.

The point is that reflexivity is not helpful in defining a notion of ontological dependence which is suitable for differentiating fictional from non-fictional characters. 
definition [D3], which captures Thomasson's own notion of generic dependence, is not sufficient; that is why, as mentioned above, Thomasson links the notion of generic dependence with a specific ontology.

If we are looking for a notion such that some clearly identifiable element of a set (genus) can be said to ontologically support some object $X$, it seems natural not to include the trivial case of the object itself or even some part of it. What we need is a set of elements such that each of these, on their own, suffices for the presence of X. Moreover, because of the generic nature of this dependence, the dependence should not be determined by one single element alone, and no particular element of $\Gamma$ should (on its own) be necessary for the ontological support of X. An important addendum in the context of an artifactual approach is that both the supporting and the supported entities are artifacts that are uniformly, historically and rigidly dependent upon one and the same entity. These considerations lead us to the following definitions:

[D6] [Generic Constant DePendence] Let $\Gamma \cup\{\mathrm{X}\}$, where $\Gamma$ is of a size greater than 1 , $\mathrm{X} \notin \Gamma$ and $\mathrm{X}$ is not part of any $\mathrm{Z}$ in $\Gamma$. X GENERICAlly CONSTANTLY DEPENDS ON $\Gamma$ at $w_{0}$ iff the following conditions hold for all worlds $w$ R-accessible from $w_{0}$, and all times $t$ :

(1) if $X \in D_{w, t}$, then there is a $Y \in \Gamma$ such that $Y \in D_{w, t}$;

(2) every $\mathrm{Z}$ in $\Gamma$ locally requires $\mathrm{X}$ in $w$ at $t$;

(3) there is at least one $w$ accessible from $w_{0}$ such that $\mathrm{X}$ does not locally require $\mathrm{Z}_{\mathrm{i}}$ (but some $\mathrm{Z}_{\mathrm{j}} \neq \mathrm{Z}_{\mathrm{i}}$ ) in $w$ at $t$.

By condition (1), there is, for every $w$ R-accessible from $w_{0}$ and every $t$, at least one supporting individual in $\Gamma$, given that $\mathrm{X}$ constantly depends on $\Gamma \cdot{ }^{34}$ By condition (2), again,

\footnotetext{
${ }^{34}$ To keep matters simple, in the present definition, we considered that the set $\Gamma$ contains objects of only one sort, namely, copies of the same relevant text (in Thomasson's terminology, copies of the same composition). However, the set might contain copies and readers, or we can think of $\Gamma$ as being a class of sets, readers and copies.
} 
each individual $\mathrm{Z}$ of $\Gamma$ suffices alone to support the existence of $\mathrm{X}$ in every world-time pair in which $\mathrm{Z}$ exists. Condition (3) ensures that the supported entity is not required for any entity in particular. Take for example the case of Holmes, and copies of the work as constituting the genus. The genus will not contain the fictional character Holmes itself (but copies of the work where Holmes occurs). By the second condition, every copy requires Holmes locally, that is at a given $w, t$ point, although, by condition (3), it does not necessarily require the support of the copy $Z_{i}$. However, it does require one of the Zs. Thus, according to condition (3), Watson is not suitable as an element of the genus that ontologically supports Holmes because he is compresent with Holmes, as is every other fictional entity of the work Sherlock Holmes (see comments to objection b in section 4 above). Condition (2) rules out explicitly that parts of a whole, such as in the example of Theseus' ship generically support a given entity (see objection e in section 4 above): a part of the ship (without the others) is not sufficient to ontologically support the ship. ${ }^{35}$

Let us now add the artifactual aspect.

[D7 ] [ARTifactual Generic Constant Dependence] Let $\Gamma \cup\{X\}$, where $\Gamma$ is of a size greater than $1, \mathrm{X} \notin \Gamma$ and $\mathrm{X}$ is not part of any $\mathrm{Z}$ in $\Gamma . \mathrm{X}$ is in a relation of ARTIFACTUAL GENERIC CONSTANT DEPENCE ON $\Gamma$ at $w_{0}$ iff

(1) it is in a relation of GENERIC CONSTANT DEPENDENCE ON $\Gamma$;

(2) every $\mathrm{Z}$ in $\Gamma$ is uniformly, historically and rigidly dependent upon the same entity as $\mathrm{X}$.

\footnotetext{
${ }^{35}$ Definition [D6] involves a stronger link between the supported and the supporting entities than the link established in Thomasson's approach. In fact, our notions of ontological dependence do not possess the same mathematical properties as Thomasson's relations of existential dependence. The point is that Thomasson [1999: 34-35] needs these properties in order to structure her underlying ontology. However, since we do not assume this ontology, our notions will not share the same properties.
} 
The preceding definitions lead to the following notions on independent and dependent entities.

\section{Independent, Dependent and Fictional Characters}

[D8] [INDEPENDENT ENTITY] The individual $X$ is an INDEPENDENT ENTITY at $w_{0}$ iff there is no set $\Gamma$ on which $\mathrm{X}$ generically constantly depends at $w_{0}$.

[D9] [ARTIFACtuAlly DePENDENT ENTITy] We say that an object X is an ARTIFACTUALly DEPENDENT ENTITY at $w_{0}$ iff the two following conditions hold:

(i) there is at least one individual $\mathrm{Y}$ such that $\mathrm{X}$ UNIFORMLY, HISTORICALLY AND RIGIDLY DEPENDS on Y at $w_{0}$;

(ii) there is at least one genus set $\Gamma$ such that $X$ is in a relation of ARTIFACTUAL CONSTANT GENERIC DEPENDENCE on $\Gamma$ at $w_{0}$.

Note that definitions [D8] and [D9] involve independent and artifactually dependent entities, not literary fictional entities. Literary fictional entities are ontologically dependent entities of the actual world (in the sense of [D9]) and, according to our approach, they have the characterizing properties in the worlds (partially) described by the relevant stories.

[D10] [LITERARY FICTIONAL CHARACTER] We say that an object X is a LITERARY FICTIONAL

\section{CHARACTER iff}

(1) it is an artifactually dependent entity;

(2) it has the characterizing properties in the worlds (partially) described by the relevant stories. $^{36}$

In the present paper we deal with the ontological properties of a literary fictional entity, i.e., condition (1) of [D10]). In order to implement the second condition we need to examine

\footnotetext{
${ }^{36}$ The point is that although Thomasson might reject the second condition of [D10], the formal modal semantics of ontological dependence of the Artifactual Theory seems to require it - at least in our framework and in the context of our notion of codification (see section 5.1 above). In fact, Voltolini, too [2006: part I, chapter 3], suggests that an artifactual approach requires such a condition, although his argument is based on identity issues.
} 
its semantic properties, i.e., how such entities contribute to the meaning of propositions that refer to them. This would involve developing the semantics of an adequate fictionality operator, but fictional operators will not be addressed in the present paper.

\section{Meinongians and Non-Meinongians: Beyond the Artifactual Theory}

In the above sections we developed a notion of ontological dependence compatible with the realist position of Thomasson, according to which ontologically dependent entities, including fictional entities, are as existent as ontologically independent ones. Modal Meinongians of various veins, such as Graham Priest [2005], Francesco Berto [2008, 2011], or Edward Zalta [1983, 1988], reject this form of realism. However, it is not difficult to adapt the above definitions to the Meinongian approach. We distinguish two types of quantification: one which applies solely to independent entities, and a second, more general in scope, which applies to fictional (in the sense of [D9]) and independent entities. The difficulty is that many Meinongians might resist the idea of considering non-existents as ontologically dependent objects. Yet in principle, there is nothing against taking mere possibilia to be artifacts. Priest and Berto, for example, seem not to reject this approach. Indeed, Priest [2011] has already developed a version of Noneism for increasing domains, that is, a modal frame extended with a domain which contains constructions.

Voltolini [2006: 65-100 and 187, 220] develops a syncretistic theory of fictional characters that combines a Neo-Meinongian approach with the Artifactual Theory. One of its main metaphysical points is, basically, that constant ontological dependence is defined as a relation between the fictional character and the (continuous) process of make-believe. It seems that our modal semantics for constant dependence could also be applied, mutatis mutandis, to Voltolini's approach. However, the problem will be to formulate the semantics in such a way that it captures the double process of make-believe assumed by Voltolini. 
One might even defend a non-Meinongian position - such as that held by Stephen Read [1995] - so that we quantify only over independent entities, although individual constants might also refer to ontologically dependent entities.

Last but not least, our definitions are also compatible with the supervaluational interpretation of inner and outer domains of Bencivenga [1986] - see Fontaine and Rahman [2012].

\section{Conclusions and Work Ahead}

The main aim of the present paper was to define relevant ontological dependences in order to characterize fictional entities in a modal framework without Thomasson's assumptions of a primitive class of concrete entities.

As mentioned above, in the present paper we deal with the ontological properties of a literary fictional entity. What is now needed is an examination of its semantic properties, i.e., how such entities that result from a codification act contribute to the meaning of propositions that refer to them and how identity is to be understood in such a framework. This involves the introduction of an adequate fictionality operator, the semantics of which has been developed in an unpublished paper by Rahman and Tulenheimo [2009], and which has been studied further in two recent papers by the authors of the present paper [2010, 2012]. In her study on identity criteria of fictional entities, Thomasson [1999] combines the Artifactual Theory with a fictionality operator. Her strategy gives rise to several objections that in our view could be solved by extending the notion of individual as described in the Artifactual Theory. This requires abandoning Kripke’s semantics and casting the modal semantics in the framework of Hintikka's notion of world-lines, where an individual is understood as a (partial) function that takes as its value one object of the domain of a given world or scenario $w$, called the manifestation or aspect of the individual at w,t (e.g., the individual that "manifests" as a 
detective at $w, t) .{ }^{37}$ Although the semantics of such a conception of an ontologically dependent individual has been developed by Fontaine and Rahman [2012] in a recent paper, a thorough study that integrates the notion of ontological dependence with the fictionality operator and the notion of individuality should be undertaken in further research.

Furthermore, we have been using a model-theoretical semantics although in fact at least one of the authors is firmly convinced that the whole approach should be developed in a different framework - a dialogical one - and within the setting of a fully interpreted language, such as the type-theoretical grammar of Aarne Ranta. ${ }^{38}$ This should provide both a theory of meaning and a theory of inferences involving fictional entities, and such an exploration is the subject of ongoing research projects. ${ }^{39}$

Acknowledgments: The authors are indebted to Tero Tulenheimo for his valuable input during the initial stages of writing, to two anonymous referees for crucial remarks and to Gareth Wilson and Cheryl Lobb de Rahman for linguistic and stylistic corrections.

\section{References}

Bencivenga, E. 1986. Free Logics, in Handbook of Philosophical Logic vol.3, D. Gabbay and F. Guenther, eds, Dordrecht: Reidel: 373-426.

Berto, F. 2008. Modal Meinongianism for Fictional Objects, Metaphysica 9: 205-18.

Berto, F. 2011. Modal Meinongianism and Fiction: The Best of Three Worlds, Philosophical Studies 152: 313-35.

Cameron, R. 2008. Turtles All The Way Down: Regress, Priority and Fundamentality, Philosophical Quarterly 58: 1-14.

Correia, F. 2005. Existential Dependence and Cognate Notions. Munich: Philosophia Verlag.

\footnotetext{
${ }^{37}$ Priest [2011, section 2.9] uses a similar approach, though he assumes rigid designation.

${ }^{38}$ Ranta [1994], chapter 6.9 and 7.3.

${ }^{39}$ For dialogical approaches to the logic of fictions see Fontaine and Redmond [2012] and Redmond [2011].
} 
Correia, F. 2008. Ontological Dependence, Philosophy Compass 3 (5): 1013-32.

Fine, K. 1995. Ontological Dependence, Proceedings of the Aristotelian Society, New Series 95, Blackwell Publishing: 269-90.

Fine, K. 2001. The Question of Realism, Philosophers Imprint 1, 1-30.

Fontaine, M. and Rahman, S. 2010. Fiction, Creation and Fictionality: An Overview, Methodos, 10, accessed April 2010, URL=http://methodos.revues.org/2343.

Fontaine, M. and Rahman, S. 2012. Individuality in Fiction and the Creative Role of the Reader, Revue Internationale de Philosophie, 4 (262): 539-560.

Fontaine, M. and Redmond, J. 2012. To be is to be chosen, in Logic of Knowledge, C. Barés Gómez, S. Magnier, F. Salgero, eds., London: College Publications: 203-220.

Ingarden, R. 1931. Das literarische Kunstwerk. Eine Untersuchung aus dem Grenzgebiet der Ontologie, Logik und Literaturwissenschaft. Halle: Max Niemeyer.

Ingarden, R. 1968. Vom Erkennen des literarischen Kunstwerks. Tübingen: Max Niemeyer. Jenking, C.S. 2001. Is Metaphysical Dependence Irreflexive?, The Monist 94: 267-76.

Kripke, S. 1980. Naming and Necessity, Harvard: Harvard University Press.

Kroon, F. and Voltolini, A. 2011. Fiction, The Stanford Encyclopedia of Philosophy (Fall 2011 Edition), ed. Edward N. Zalta, URL = http://plato.stanford.edu/archives/fall2011/entries/fiction/.

Lewis, D. 2003. Things Qua Truthmakers, in Real Metaphysics: Essays in Honour of D.H. Mellor, H. Lillehammer and G. Rodriguez-Pereyra, eds, London: Routledge: 25-38.

Lowe, E.J. 1994. Ontological Dependency, Philosophical Papers 23: 31-48.

Lowe, E.J. 1998. The possibility of Metaphysics, Oxford: Oxford Clarendon Press. 
MacDonald, M. 1954. The Language of Fiction, Proceedings of the Aristotelian Society, Supplementary Volume 27, Blackwell Publishing: 165-96.

McLaughlin, B. and Bennett, K. 2005. Supervenience, The Stanford Encyclopedia of Philosophy (Winter 2011 edition), ed. E. N. Zalta, URL: http://plato.stanford.edu/archives/ /win2011/entries/supervenience/.

Parsons, T. 1988, Nonexistent Objects, New Haven: Yale University Press.

Priest, G. 2005, Towards Non-Being: The Logic and Metaphysics of Intentionality, Oxford, Clarendon Press.

Priest, G. 2011, Creating Non-Existents, in Truth in Fiction, ed. F. Lihoreau, Frankfurt: Ontos Verlag: 107-18.

Rahman, S. and Tulenheimo, T., 2009, Fictions as Creations and the Fictionality operator, unpublished manuscript.

Ranta, A. 1994. Type-Theoretical Grammar, Oxford: Clarendon Press.

Read, S. 1995. Thinking About Logic, Oxford: Oxford University Press.

Redmond, J. 2011. Logique Dynamique de la Fiction, London: College Publications.

Rosen, G. 2010. Metaphysical Dependence: Grounding and Reduction, in Modality, B. Hale and A. Hoffman, eds, Oxford: Oxford University Press, 109-35.

Schaeffer, J.-M. 1999. Pourquoi la fiction? Paris: Seuil.

Schaffer, J. 2009. On What Grounds What, in Metametaphysics, D. Chalmers, D. Manley and R. Wasserman, eds, Oxford: Oxford University Press, 347-83.

Simons, P. 1987. Parts. A Study in Ontology, Oxford: Clarendon Press.

Thomasson, A. L. 1999. Fiction and Metaphysics. Cambridge: Cambridge University Press. 
Thomasson, A. L. 2003. Speaking of Fictional Characters, Dialectica 57: 207-226.

Thomasson, A. L. 2010. Fiction, existence et référence. Methodos 10, accessed April 2010, URL: http://methodos.revues.org/2446.

Voltolini, A. 2006. How Ficta Follow Fiction: A Syncretistic Account of Fictional Entities, Dordrecht: Springer.

Walton, K. L. 1990. Mimesis as Make-Believe. On the Foundations of Representational Arts, London: Harvard University Press.

Zalta, E.N. 1983. Abstract Objects: An Introduction to Axiomatic Metaphysics, Dordrecht: Reidel.

Zalta, E.N. 1988. Intentional Logic and the Metaphysics of Intentionality, Cambridge, Mass: MIT Press. 